Article

\title{
The Use of Thermal Infra-Red Imagery to Elucidate the Dynamics and Processes Occurring in Fog
}

\author{
Jeremy Price ${ }^{1, *}$ and Kristian Stokkereit ${ }^{2}$ \\ 1 Met Office, EX1 3PB Exeter, UK \\ 2 Department of Physics, University of Surrey, GU2 7XH Guildford, UK; ks00473@surrey.ac.uk \\ * Correspondence: jeremy.price@metoffice.gov.uk
}

Received: 15 January 2020; Accepted: 17 February 2020; Published: 29 February 2020

\begin{abstract}
Improving our ability to predict fog accurately is currently a high priority for Numerical Weather Prediction models. Such an endeavour requires numerous types of observations of real fog as a means to both better understand it and also provide an assessment of model performance. We consider the use of thermal infra-red imagery, used in conjunction with other meteorological observations, for the purposes of studying fog. Two cameras were used-a FLIR Systems Inc. A655sc and a FLIR Systems Inc. A65sc-which were set up to capture one image per minute. Images were then combined to provide video footage of nocturnal fog events. Results show that the imagery from such cameras can provide great insight into fog processes and dynamics, identifying interesting features not previously seen. Furthermore, comparison of imagery with conventional meteorological observations showed that the observations were often not capable of being used to delineate all of the processes affecting fog, due to their incomplete and local nature.
\end{abstract}

Keywords: fog; fog dynamics; infra-red imagery; infra-red camera

\section{Introduction}

The impact of fog reaches across many aspects of human society, and has become more prevalent in recent years, principally due to the growth of the transport industry, and in particular aviation [1]. The financial implication for the aviation industry can be large, for example the financial losses accrued at Gandhi International Airport in India, between 2011 and 2016, amounted to approximately 3.9 million USD to airlines [2]. The disruption to surface traffic is also significant, for example, in the US, between 1995 and 2004, 13,720 people were reported to have died in fog-related accidents [3]. Dense, radiatively cooling fog can also lead to persistent inversions which can result in pollution remaining in the lower atmosphere for extended periods with consequences for human health [4]. Other important aspects of fog include its occurrence over arid regions, where fog water is collected as an additional water source [5]. In the Mountain cloud forests of Taiwan, fog is a regulator for the entire ecosystem [6], and in California's central valley, daytime fog prolongs the winter chill essential for improving crop yield in the following season's fruits [7].

Therefore, it is clear that fog is an important atmospheric phenomenon and that understanding its lifecycle and, in particular, predicting that lifecycle are important goals for weather service providers. Despite this, there is scope for improving numerical forecasting of fog, which remains a challenge to predict accurately [8]. Observations remain a key asset for model development by providing both comparative data sets and also new insights into fog behaviour. However, traditional in situ observations can sometimes lack the spatial or temporal coverage required to provide a complete analysis. In this regard, new remote sensing technologies show significant potential to provide a synergistic combination with traditional instrumentation to help us obtain a fuller understanding of fog lifecycles. 
In this paper, we present results from the use of an infra-red (IR) thermal imaging camera, used in conjunction with in situ meteorological instruments and demonstrate how it can add significantly to the analysis of fog cases, allowing deductions not possible with traditional in situ equipment alone.

\section{IR Camera Specification, Set up and Analysis}

IR cameras can be classified into two types, depending on whether the sensor is cooled or not. Whilst cooled types have a large temperature range, and are capable of better accuracy with lower noise, they are expensive. Fortunately, the cheaper un-cooled types are usually of sufficient quality for fog research, though may require regular calibration, and post-priori corrections if quantitative temperature information is required. Here, we present results from two FLIR Systems, Inc. IR camera systems, both with un-cooled sensors (A65s and A655s). The basic properties of these cameras are given in Table 1.

Table 1. Details of the two infra-red (IR) cameras used.

\begin{tabular}{ccc}
\hline FLIR & A65s & A655s \\
\hline Accuracy, ${ }^{\circ} \mathrm{C}$ & 5 or $5 \%$ & 2 or $2 \%$ \\
Sensitivity, ${ }^{\circ} \mathrm{C}$ & 0.05 & 0.03 \\
Range, ${ }^{\circ} \mathrm{C}$ & -12 to 135 & -40 to 150 \\
Image resolution & $640 \times 512$ & $640 \times 480$ \\
Spectral range, $\mu \mathrm{m}$ & 7.5 to 13 & 7.5 to 14 \\
Acquisition rate, $\mathrm{Hz}$ & 9 & 50 \\
Angle of view, ${ }^{\circ}$ & 45 & 45 \\
\hline
\end{tabular}

Of the two systems, the A655s provides more accurate measurements and slightly improved sensitivity, but at increased cost and physical size. Calibration checks are performed against a black body target, and pixel-to-pixel correction can be performed with the manufacturer's software provided if required. Additionally, the cameras perform periodic internal calibrations. Cameras are mounted in standard CCTV housings for protection, but with germanium windows fitted. Images from the cameras are recorded on a computer using proprietary software supplied by the manufacturer. Images and videos presented are also derived from this software, which can also be used for basic analysis of the images. The cameras can be operated continuously, and the image capture rate can be set by the user. For fog studies, we have chosen a capture rate of one per minute, which allows sufficient time resolution for video footage whilst preventing prohibitively large data files. However, for continuous operation, it is advisable to reset the data logging periodically (e.g., once per month) in order to prevent excessively large data files. The system benefits from low power drain, and cameras can be operated in the field for periods of a few days using suitable batteries. Figure 1 shows a deployment of the A655s camera in the field during a recent campaign (the Local And Non local Fog EXperiment (LANFEX); see Section 3.1). This system uses $300 \mathrm{Ah}$ of lead-acid batteries (12V) which provide enough power for 3-4 days of operation. Due to the large size of data files, data are retrieved manually from the system at regular intervals. 


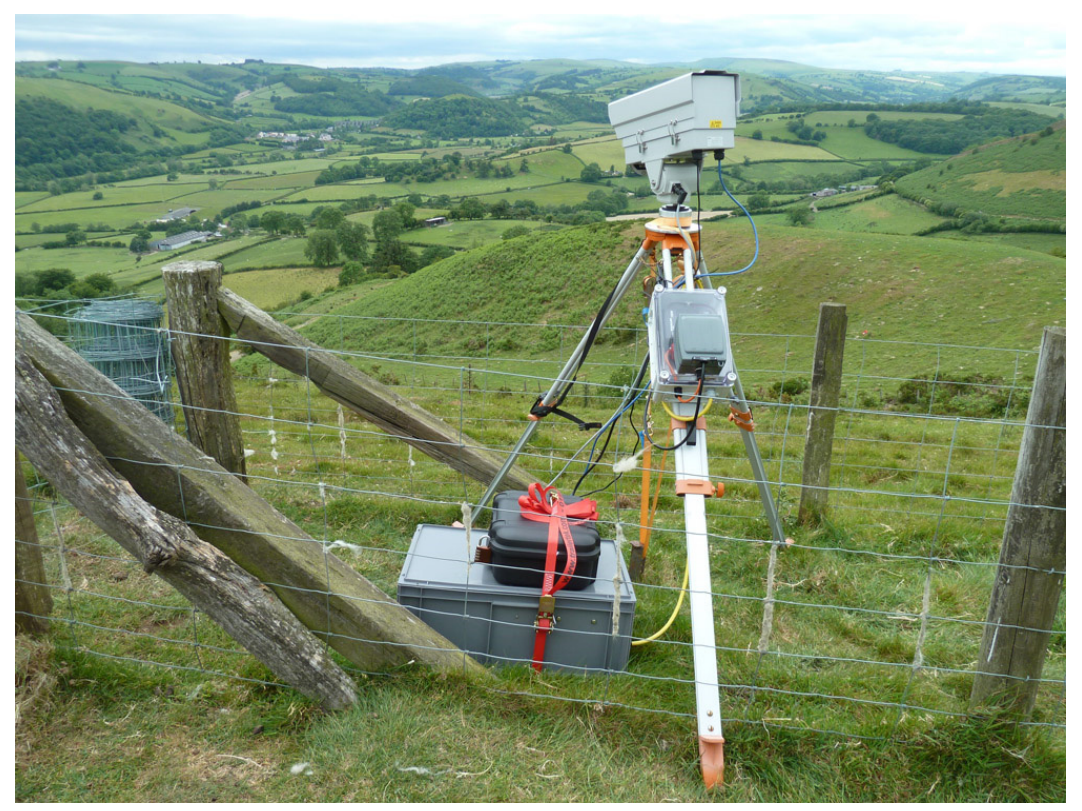

Figure 1. Showing deployment of the mobile IR camera system at Skyborry during the Local And Non local Fog EXperiment (LANFEX). The area covered by the IR images shown in Section 3.1 lie to the left of the camera in this image.

The spectral sensitivity of these cameras falls within an atmospheric window, which allows the detection of objects out to several $\mathrm{Km}$ before atmospheric emissions reduce contrast and image quality (and often introduce a positive bias to retrieved temperatures). Since shallow radiation fog is not optically thick, it is generally difficult to detect with these systems until it reaches 5-10 m deep, after which it is usually seen as a region of cooler temperature, contrasting against warmer surroundings.

All meteorological data presented, except vertical velocity variance $\left(\sigma_{\mathrm{w}}{ }^{2}\right)$, are averaged over $10 \mathrm{~min}$, except where otherwise stated. $\sigma_{\mathrm{w}}{ }^{2}$ is averaged over $30 \mathrm{~min}$. Winds were measured by Gill HS50 sonic anemometers, temperature using platinum resistance devices (PT100 IEC60751 'A'), humidity using Vaisala HPM155 probes, and visibility with Belfort 6230A and Biral VPF-7230 probes. More information regarding the meteorological measurements presented can be seen in Price et al. [9].

\section{Results}

In this section, we provide examples of the use of IR cameras for fog studies which help to elucidate the wide range of dynamics occurring in nocturnal boundary layers.

\subsection{Fog Dynamics in Complex Terrain}

In 2014-2016, the Met Office conducted the LANFEX campaign—of which, one field component was located in Shropshire, England [9]. The deployment included an IR camera placed on a hilltop overlooking the Teme valley at Skyborry. An example of a typical fog case for this valley is presented here and illustrates the complex flow normally seen in such locations. Of particular interest is the interaction of fog which formed in a tributary valley with that in the main valley. Figure 2 shows a sequence of images captured from the IR camera for a case of radiation fog, occurring 18-19 September 2015. In these images fog is displayed by elevated regions in the valleys coloured purple.

Figures 3 and 4 show visibility and temperature respectively, measured on the main valley floor (their location is indicated in Figure 2, panel (a)). These observations form part of an extensive range of observations made here which are detailed in [9]. The data show a typical stable boundary layer (SBL) development, where a moderately stable nocturnal boundary layer formed during the night with a weak down valley drainage flow forming within it (not shown). Persistent fog did not form before approximately 0400 UTC. 

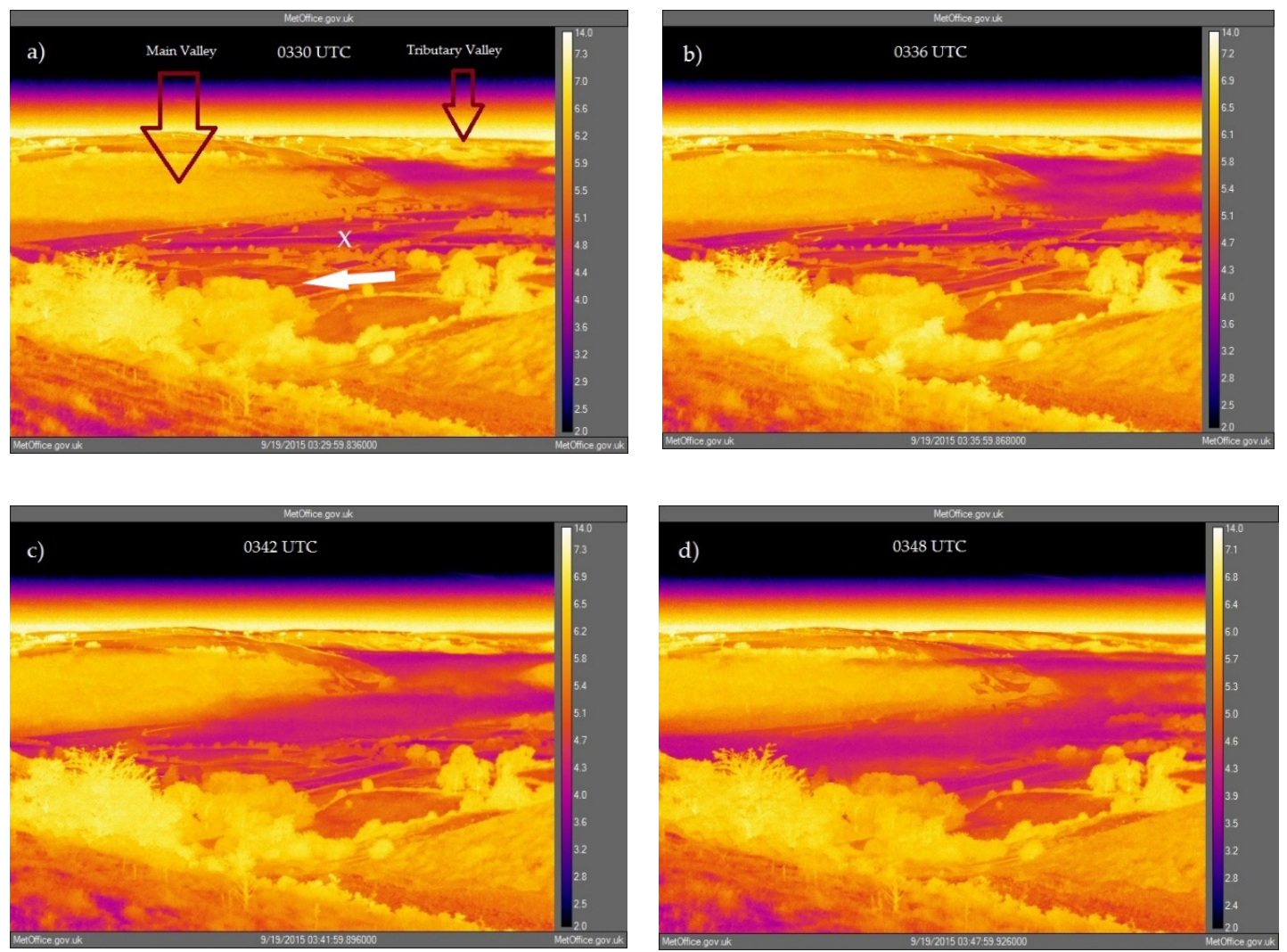

Figure 2. IR images taken during the LANFEX, 18-19 September 2015, at Skyborry for, (a) 0330 UTC, (b) 0336 UTC, (c) 0342 UTC and (d) 0348 UTC. The location of the meteorological measurement site is marked by an ' $X$ ', and the down-valley direction by an arrow in panel (a). The colour scale represents temperature (degrees $\mathrm{C}$ ).

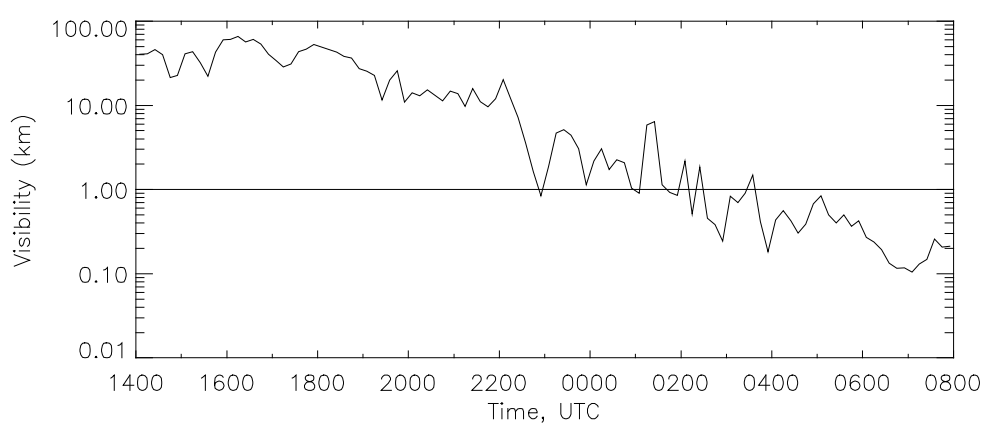

Figure 3. Visibility at Skyborry during the period 18-19 September 2015.

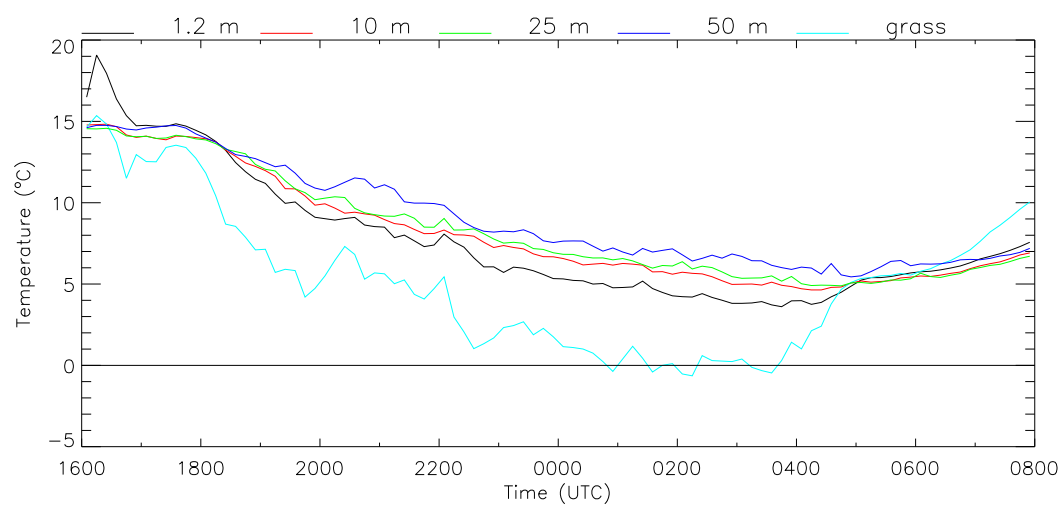

Figure 4. Temperature evolution at various levels for skyborry, 18-19 September 2019. 
Figure 2 illustrates an incursion of fog from a tributary valley into the main valley (the Teme valley at Skyborry, marked in panel (a)) which appears to be connected with the thickening of the fog in the main valley. Panel (a) shows the initial situation at approximately 0330 UTC. At this time, a deep layer of fog existed in the tributary valley, but the main valley was essentially clear. This situation has been observed on numerous occasions in this location and appears to be typical, most likely resulting from the narrower tributary valley becoming calmer earlier during the night than the main valley, allowing fog to form earlier [10]. Also note from panel (a) that the coldest temperatures are recorded for open fields on the valley floor and that there is significant inhomogeneity in the grass temperature there. In addition, the image reveals that hedgerows, trees and woodland have significantly higher skin temperatures than the valley floor and tend to reflect the temperature of the surrounding atmosphere (compare with Figure 4). Because we expect the grass to be wet with dew, and the trees may or not be wet, we expect the emissivity of the grass to be 1 , and that of the trees $<1$ or 1 . Therefore, it is not expected that the warmer trees indicated by the camera can be explained by any difference in emissivity between grass and trees. Both these results are typical for general observations of stable boundary layer (SBL) skin temperatures.

The other panels in Figure 2 show the progressive movement of fog into the main valley. Video footage of the complete fog episode can be found in the supplementary material (Video S1). This provides a much fuller and clearer illustration of the incursion, and other processes such as fog sloshing from side-to side in a seiche-like flow within the tributary valley and the dissipation of the fog during the morning period. Some results which can be summarized are:

1. Fog typically forms in the tributary valley before the main valley and displays interesting dynamics including 'sloshing'.

2. Fog does not appear to drain continuously from the tributary valley into the main valley but does so episodically: two incursions are evident in the video.

3. The effect of the incursions on the meteorological date are very subtle: it is not possible to deduce the dynamics revealed in the video footage from the meteorological data. For the case in Figure 2, the largest noted effect was a rise in grass temperature (Figure 4).

4. Shortly after the incursion noted in Figure 2 advection of deep fog from further up the main valley is evident.

5. During the morning break up of the fog, the height of the fog top is seen to decrease, which appears to contradict the perhaps more expected situation where the boundary layer warms and deepens via convection.

The result of (2) and (4) is intriguing but, as will be seen from later sections, appears to be a common occurrence, whereby fog deepens due to a relatively abrupt advective event. The dynamic trigger for these events appears to be poorly understood, but could be supposed to be due either to the way in which buoyancy effects manifest (e.g., a gravity current), or perhaps a momentum effect (e.g., kinetic coupling of the fog layer with the layer above).

\subsection{Isolated Gravity Waves Revealed by Fog}

This case occurred at Cardington during the period 5-6 January 2016. The Cardington research site is located in south-east UK in a wide shallow valley approximately $10 \mathrm{~km}$ across at this location with surrounding hills rising to approximately $30-40 \mathrm{~m}$ above the valley floor. The IR camera (A65s) was mounted on the side of a local airship shed at approximately $50 \mathrm{~m}$ above ground level and overlooked the meteorological site. The case consisted of a series of isolated waves containing fog which propagated across the site during SBL conditions. Between 0300 and 0500 UTC six waves moved across the site from west to east, but previous to this the video footage reveals various waves to the south of the site which propagated from east to west. Since the visiometer recorded haze (observations of visibility ranged between $2-5 \mathrm{~km}$ ) during the period, then technically, the waves did not produce fog at the surface, but they are presented here as a curious phenomenon. Figure 5 illustrates the passage 
of one of the waves over the Cardington site. In this image, the view is southward, and the main Cardington building can be seen in the centre of the image. The meteorological instrumentation lies to the west, south and east of the main building (masts are sometimes visible in the imagery).
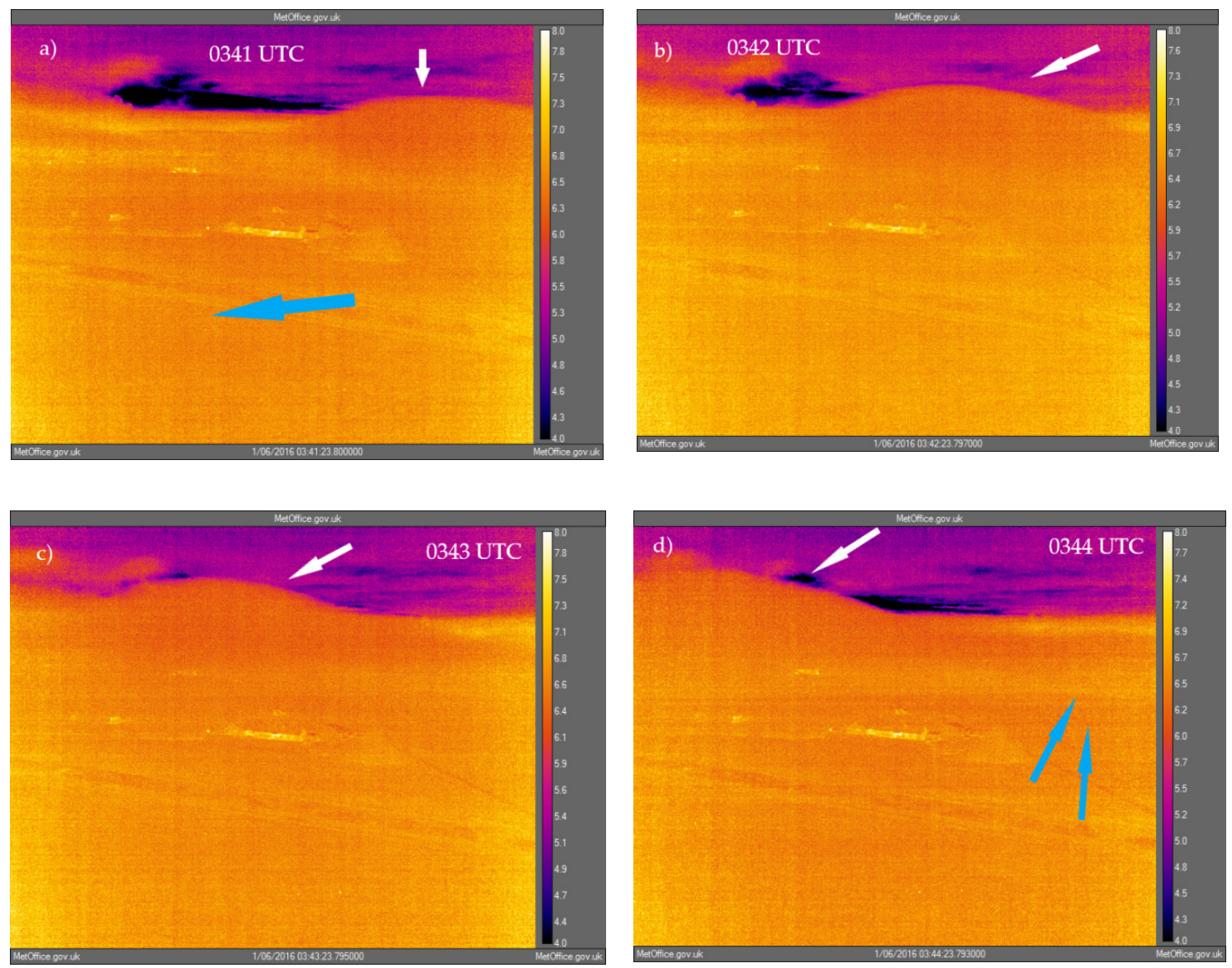

Figure 5. Illustrating the passage of an isolated gravity wave (white arrows) occurring over the Cardington site at, (a) 0341 UTC, (b) 0342 UTC, (c) 0343 UTC and (d) 0344 UTC. The blue arrow in panel (a) depicts the approximate down-valley direction. The blue arrows in panel (d) indicate the approximate locations of, temperature, humidity, wind, and visibility measurements.

Video footage of the episode can be found in the supplementary material (Video S2). Note that the waves over Cardington (0300-0500 UTC) appear to grow in height successively. The approximate heights of the wave crests are estimated from the imagery, based on landmarks and the height of the camera $(50 \mathrm{~m})$, to be 50-100 m. Meteorological data for temperature, relative humidity, wind speed and direction, turbulence intensity, downwelling long-wave radiation, and visibility were examined, but no effect of the waves on the measurements could be distinguished from the normal variations seen for the typical SBL conditions. The video therefore reveals an interesting dynamic feature which cannot be detected from standard instrumentation. The features appear to be isolated gravity waves, which presumably, as they propagate through the airmass, cause sufficient uplift to activate droplet formation (noting that ambient RH measured up to $50 \mathrm{~m}$ height was in the range $98 \%-100 \%$ for the period). This would explain why fog did not form at the surface since uplift there would be suppressed. The mechanism which creates these isolated waves in the SBL does not appear to be known, and there do not appear to be many reports of such features, though Rees at al. [11] observed what may be similar features occurring over the Antarctic ice shelf at the British Antarctic Survey observatory at Halley. 


\subsection{Dynamics of a Turbulent Fog Layer}

This case occurred during the period 3-4 October 2016 and constitutes a case where fog formed in higher wind strengths and levels of turbulence. During the night, fog was seen to form, dissipate and re-form as turbulent episodes mixed the fog upwards whereby it was advected away. Figure 6 shows some example images from the camera. Panel (a) shows the initial phase of the fog shortly after formation. During this period, homogeneous shallow fog formed in light winds and low turbulence intensity (Figure 7). However, significant wind shear existed up to $50 \mathrm{~m}$ (up to $0.085 \mathrm{~s}^{-1}$ ) such that as the fog grew upwards, it became more turbulent and inhomogeneous. Panel (b) shows the situation at 0208 UTC, with the fog top approximately $50 \mathrm{~m}$ high and turbulent mixing there clearly visible. Episodic turbulence was a pronounced characteristic of this case and is clearly visible in the video footage, which can be found in the supplementary material (Video S3). Such observations provide confirmation of the ubiquitous nature of turbulence at fog top, which can be difficult to observe (though see Cuxart and Jimenez, [12], for observations using a WindRASS) but has been readily simulated with Large Eddy Simulation models [13-15].
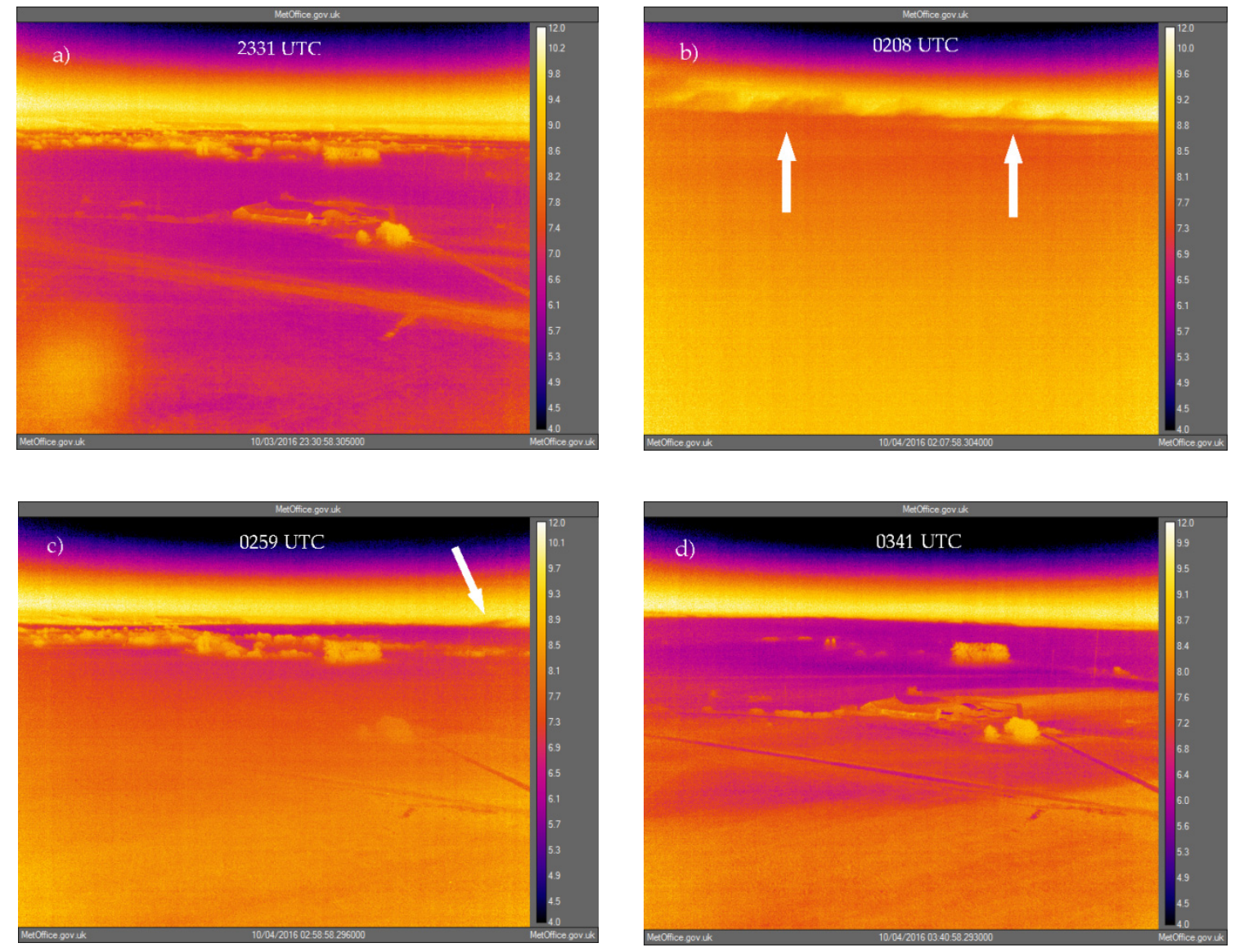

Figure 6. IR images at various stages of a turbulent fog layer occurring on 3-4 October 2016 at, (a) 2331 UTC, (b) 0208 UTC, (c) 0259 UTC and (d) 0341 UTC, as described in the text. White arrows indicate regions of mixing. The round orange area in the bottom left of panel (a) is an insect on the camera housing window. 


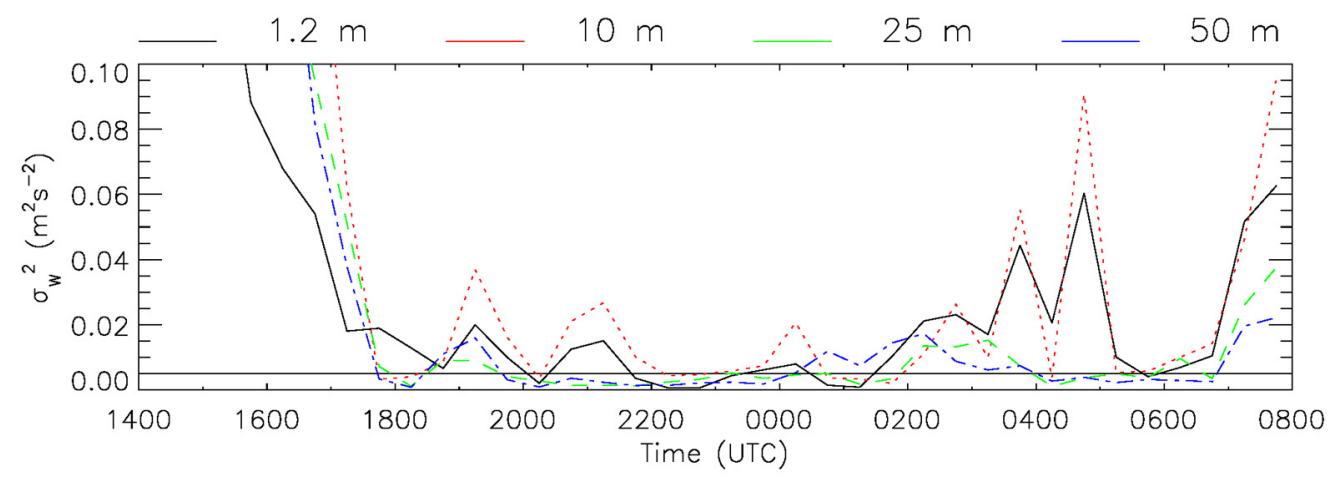

Figure 7. Vertical velocity variance for 3-4 October 2016 measured at various heights as indicated.

Panel (c) in Figure 6 shows the situation at 0259 UTC after winds at 2 and $10 \mathrm{~m}$ had increased and turbulence had reduced the vertical extent of the fog (see [10]). An area of fog can be seen to the south of the measurement site. The video imagery of this case shows that fog formed consistently in this region, grew in height, then mixed with the air above before being swept downstream (note the mixing visible on the far right of Figure $6 \mathrm{c}$ ). The video also reveals a significant amount of turbulent fog advected across the site during the night. During this episode the direction of the wind became approximately north-east at times, which meant that air flow over the measurement site periodically passed near to the airship shed on which the camera was mounted. The consequences of this can be seen in the IR imagery. Panel (d) illustrates the effect of the airship sheds on the meteorology at 0341 UTC. This occurred more frequently toward the end of the night when winds episodically backed more northerly. Note that the foreground is significantly warmer than the surroundings. This is caused by enhanced turbulence around the sheds maintaining higher temperatures there (offsetting the radiative cooling at the surface). The situation is evident in Figure 7 when, between approximately 0230 and 0530 UTC, levels of turbulence at 2 and $10 \mathrm{~m}$ were greater than at 25 and $50 \mathrm{~m}$. It is clear from the video footage why this was the case: the measurement sites at 2 and $10 \mathrm{~m}$ are situated further north than those at 25 and $50 \mathrm{~m}$, and were at times inside the wake from the sheds, whereas the latter site remained mostly at several tens of meters to the south of the wake in less turbulent air. The lower level measurements were therefore not representative of the general wider scale conditions during this period. It should be stressed that this situation is rare at Cardington and the large majority of SBL conditions remain unaffected by the airship sheds (the normal drainage flow during SBLs is from the south west). The result is consistent with other studies which show the effect of topographic features on SBL and fog development, such as that by Bergot et al. [13].

\subsection{The Effect of a Large Gravity Current on a Foggy Boundary Layer}

This case was characterized by the formation of a shallow stable layer of homogeneous fog which was interrupted by the passage of a large gravity current. The video footage of this case can be found in the supplementary material (Video S4). A relatively homogeneous fog layer formed approximately 1900 UTC and grew steadily in height, estimated at approximately $60 \mathrm{~m}$ deep by 2200 UTC. At this time, wind and levels of turbulence were increasing which acted to dissipate the fog and decrease the fog-top height. By 0000 UTC, the fog had almost gone with visibility being approximately $600 \mathrm{~m}$. The arrival of the gravity current at approximately 0020 UTC is illustrated in Figure 8. The images cover a period of five minutes, revealing that the passage of the feature was in fact quite slow. Note the distinctive 'head' at the front of the current, and the apparent turbulent mixing along its top. The video footage shows that a smaller pulse of fog moved through immediately before the one illustrated in Figure 8, and another shortly afterwards at approximately 0030 UTC. Also evident in the video is the brief formation of low cloud in front of the current. The most likely reason for this local cloud formation is that it was caused by cold air advection associated with the current undercutting and lifting the resident air such that it cooled enough to form cloud (noting that its RH was almost saturated). 

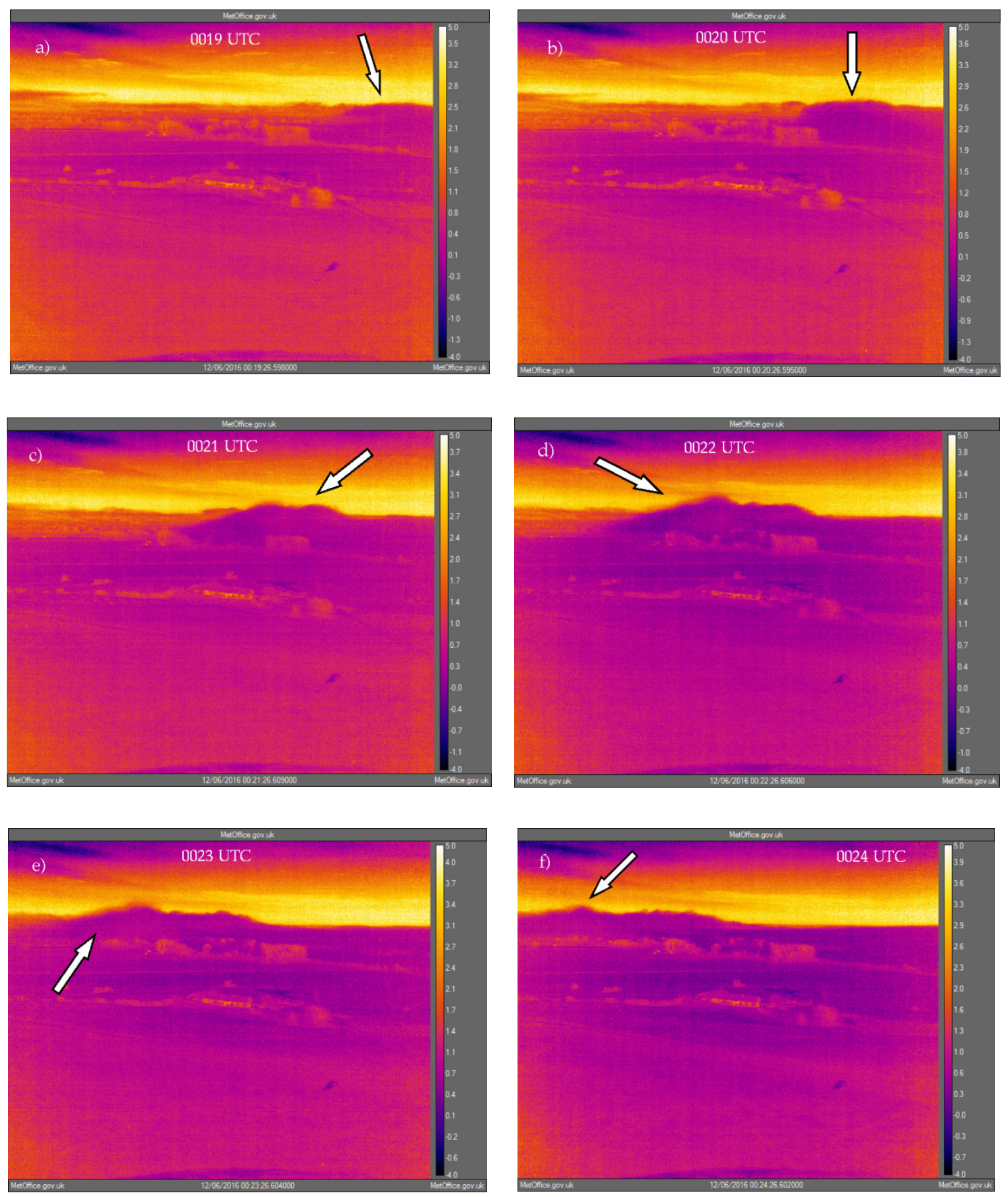

Figure 8. IR imagery illustrating the passage of a gravity current over Cardington on 6 December 2016 at (a) 0019 UTC, (b) 0020 UTC, (c) 0021 UTC, (d) 0022 UTC, (e) 0023 UTC and (f) 0024 UTC. Arrows indicate the front of the current.

Figure 9 presents the meteorological data for this case. Unlike most other cases, here, there is a clear relationship between the gravity current seen in the IR video, and the meteorological measurements, and using the measurements alone, it would be possible to deduce the passage of a gravity current. This is because the current introduced a different airmass to the site, with different properties. In particular, the temperature was seen to reduce significantly, and the wind direction reversed as the current arrived. In addition to this we see that the wind strength reduced, turbulence levels decreased markedly, and visibility reduced as thicker fog was introduced. After the current passed through, the wind direction returned to its previous value. 

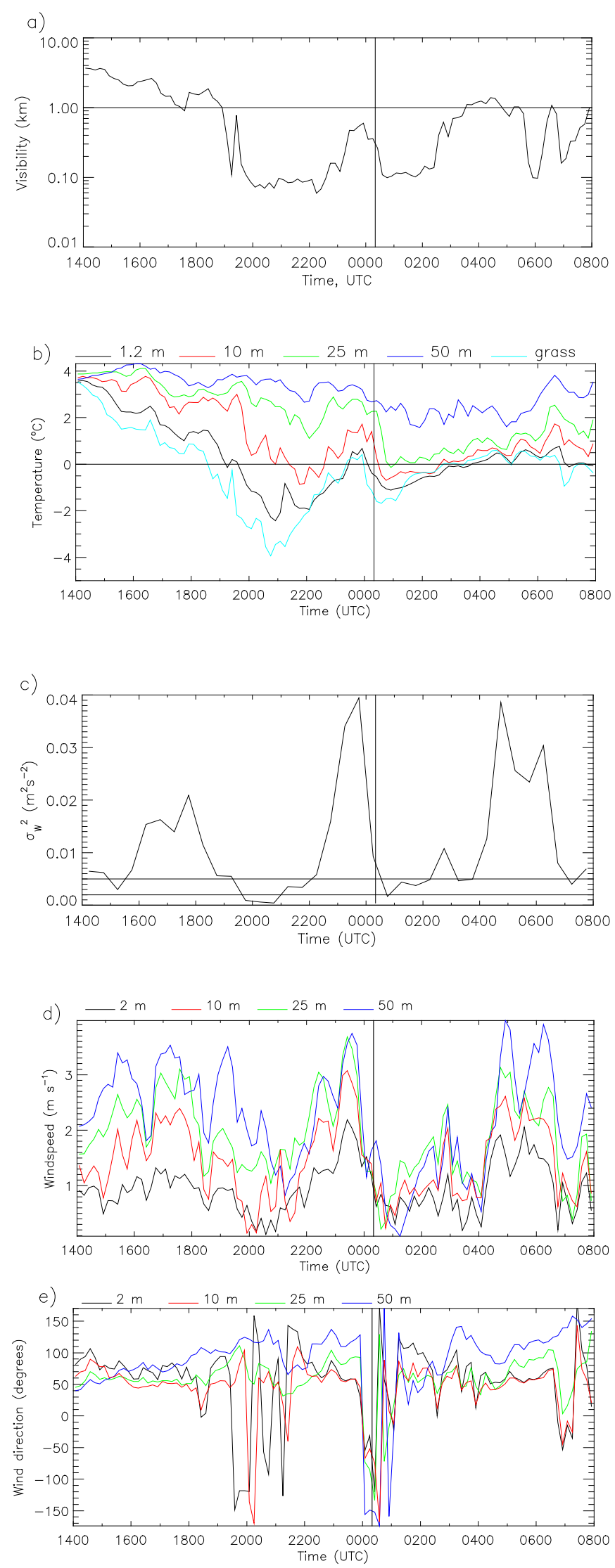

Figure 9. Meteorological data for 5-6 December 2016: (a) visibility, (b) temperature, (c) vertical velocity variance, (d) windspeed and (e) wind direction. The passage of the gravity current is indicated by the vertical black line. 


\subsection{An Example of 'Sloshing' Fog}

A case of shallow stable fog occurred on 11-12 December 2016 which displayed interesting sloshing or seiche-like flow from side to side and mixing with the air above. The layer remained very shallow at approximately $15 \mathrm{~m}$ deep and therefore represents a case where conditions were only just suitable for fog formation. It also illustrates a case of fog which was close to the shallowest limit for which the camera can usefully de-lineate the fog from its surroundings. Figure 10 presents IR imagery at one-minute intervals from approximately 0215 UTC and shows a sloshing event in the middle distance. Note evidence for mixing of the fog into the air above (e.g., panel (d)). The video footage, which can be found in the supplementary material (Video S5), shows the dynamics more clearly with fog moving over the valley floor in a seemingly random manner. At approximately 0347 UTC, a layer of fog which had existed to the south advected northwards and engulfed the shallow layer at Cardington.
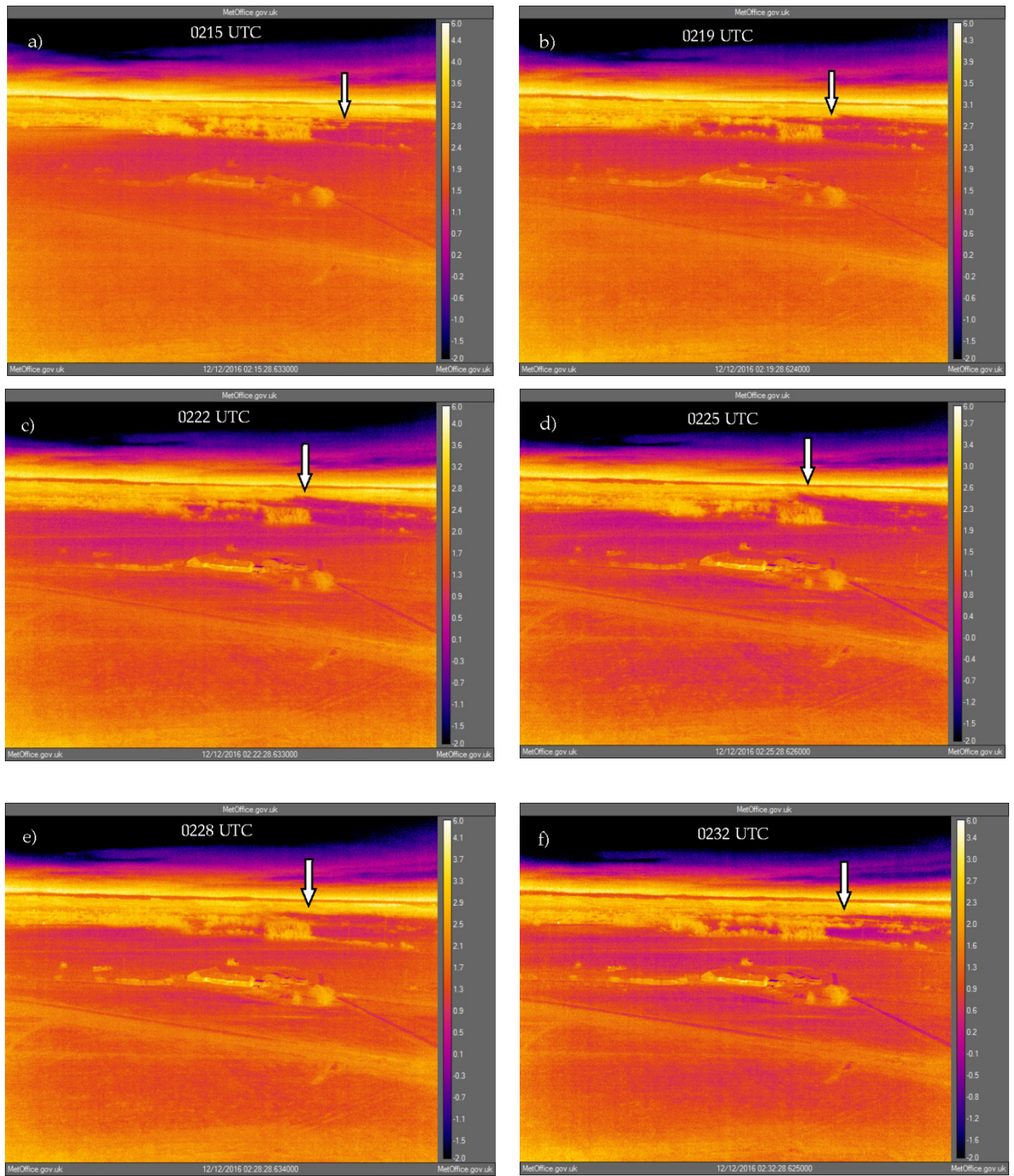

Figure 10. IR imagery for 11-12 December 2016 at (a) 0215 UTC, (b) 0219 UTC, (c) 0222 UTC, (d) 0225 UTC, (e) 0228 UTC and (f) 0232 UTC. Arrows indicate a sloshing event. 
Examination of meteorological data revealed that the characteristic of sloshing presented the strongest signal in the wind direction, with no significant perturbations visible in other parameters such as wind strength or temperature. Some meteorological data are presented in Figure 11, which shows that once the SBL had extended beyond $10 \mathrm{~m}$ depth (at approximately 1800 UTC), then the variance in wind direction increased at the lowest levels (up to $10 \mathrm{~m}$ ). Up until midnight, there was a quasi-regular oscillation with a period of approximately $30 \mathrm{~min}$. Fog formed at approximately midnight, once wind speed (Figure 11a) and levels of turbulence had decreased sufficiently. Interesting, at this point, the degree of sloshing evident in the wind direction increased markedly, most likely as a consequence of the decreasing wind strength, but note that it was restricted to heights below $25 \mathrm{~m}$. The video footage for this case indicates that the scale of 'sloshing' was of the order of a few hundred meters.
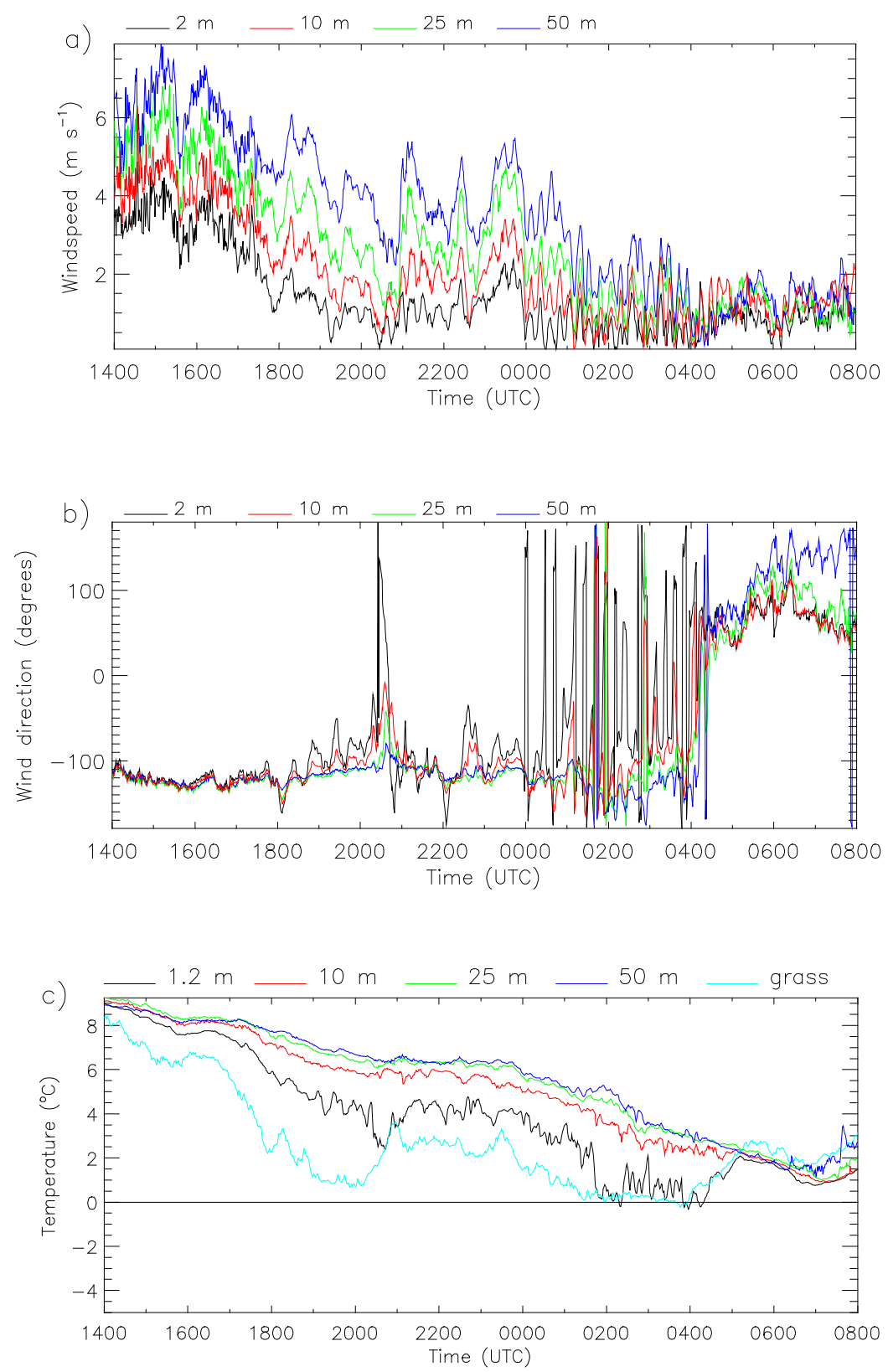

Figure 11. Meteorological data for 11-12 December 2016: (a) windspeed, (b) wind direction and (c) Table 1. min averages. 
A possible consequence of the fog dynamics evident from the video footage is the potential for significant deposition of fog droplets onto vegetation as it either sloshes back and forth or is carried by the larger-scale flow. This may be large enough to alter the properties of the fog. Deposition of fog droplets onto flat grass surfaces has been characterized by, e.g., Price [10], but there appear to be fewer studies considering deposition onto trees, shrubs and hedgerows despite various modelling studies indicating its importance [16,17]. Tav et al. [18] and Vermeulen et al. [19] present observations of fog deposition onto small trees and forest, respectively and whilst such studies generally conclude that in non-arid regions the fog water flux is small in comparison to other processes such as precipitation, the effect of the deposition on the fog layer itself appears to remain largely unstudied.

\subsection{A Layer of Long-Lived Inhomogeneous Fog}

This case, which occurred during the period 27-28 December 2016, is presented to illustrate the complexity of flow within a fog throughout its lifetime. During this case, fog formed, cleared and reformed several times, with depths up to $50 \mathrm{~m}$ deep. Many of these transitions appeared to be due to advection within the valley. The early fog before approximately 2130 UTC was not well delineated in the IR imagery, due to its very shallow nature. However, after this time, patches of fog were seen advecting around the valley floor. Figure 12 shows examples of IR imagery throughout the fog lifetime. Video footage of the complete fog episode can be found in the supplementary material (Video S6). The corresponding meteorological data are presented in Figure 13.
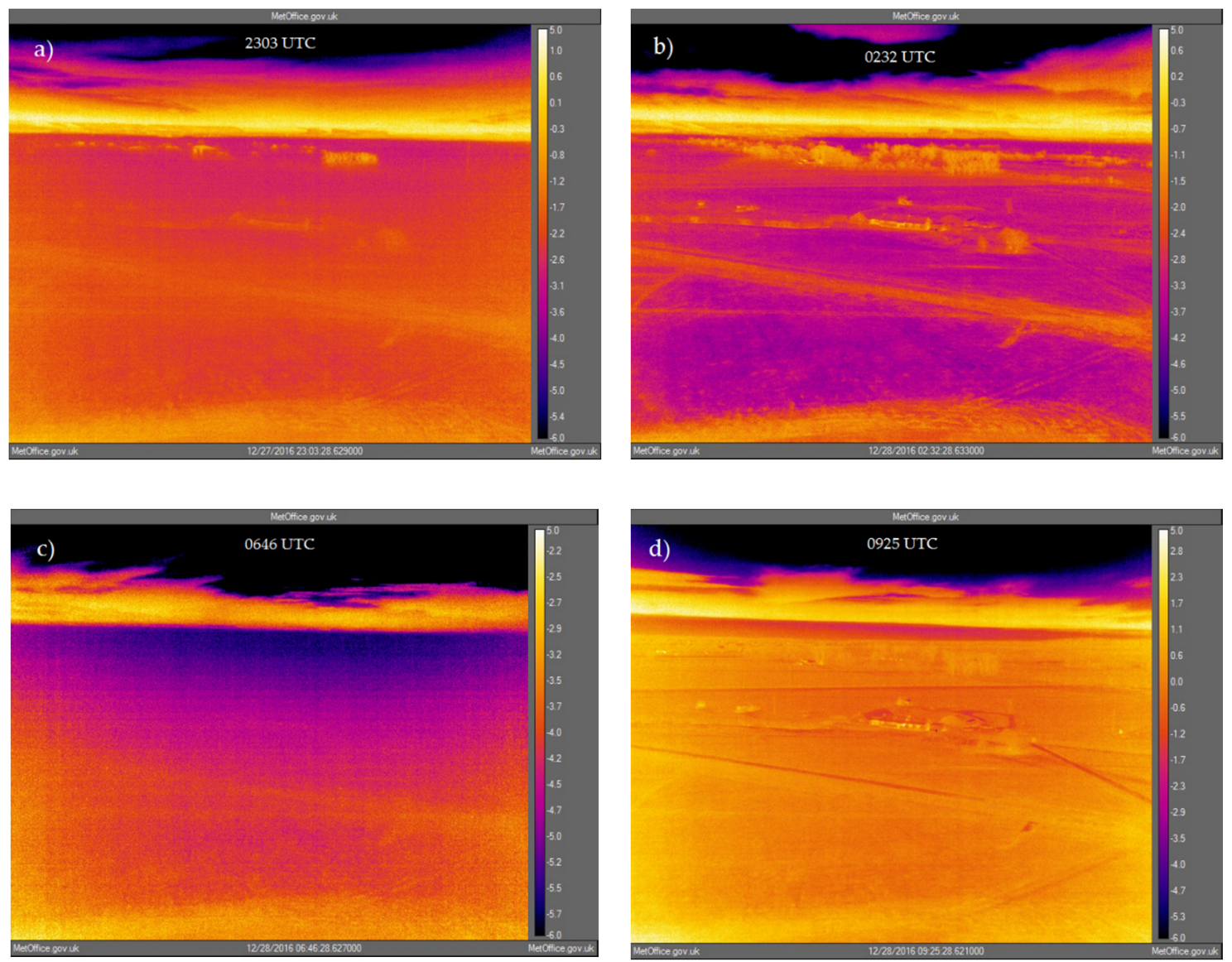

Figure 12. IR imagery for 27-28 December 2016 at (a) 2303 UTC, (b) 0232 UTC, (c) 0646 UTC and (d) 0925 UTC. 

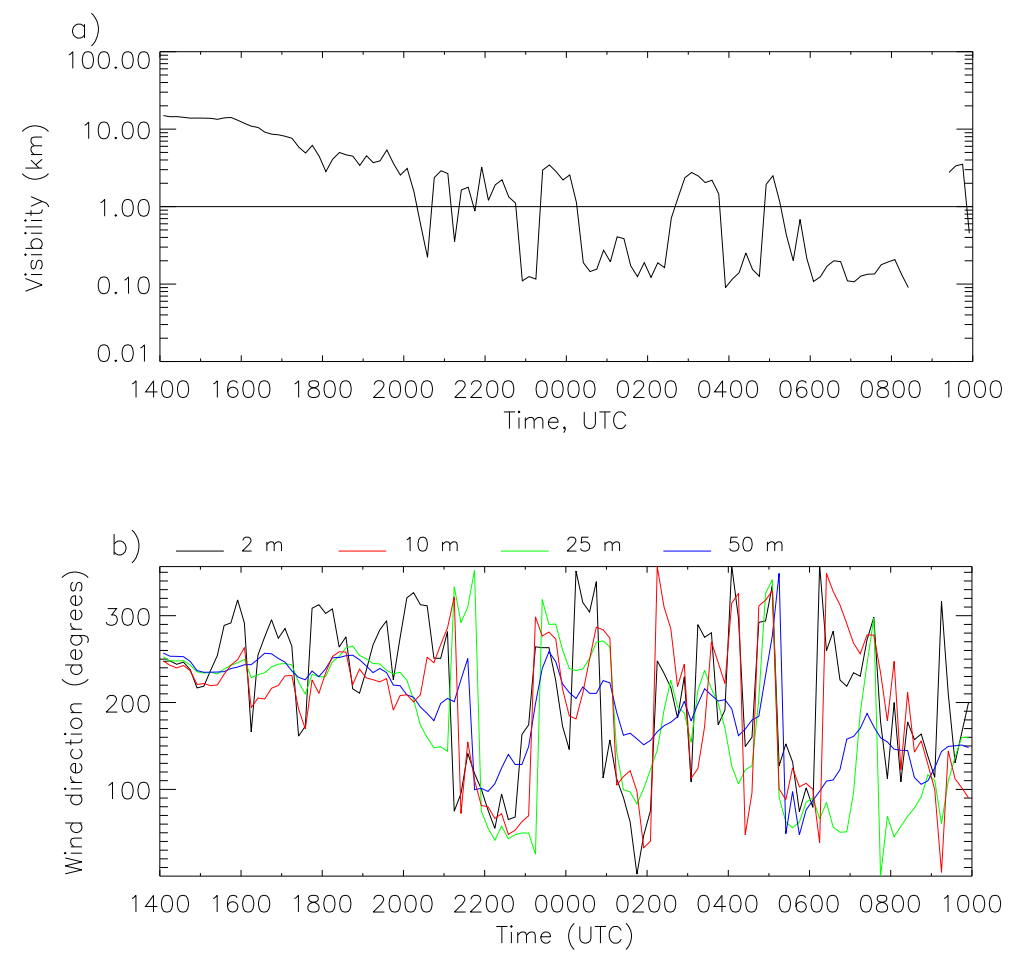

Figure 13. Meteorological data for 27-28 December 2016: (a) visibility and (b) wind direction.

The visibility data (Figure 13, panel (a)) illustrate the inhomogeneous nature of the fog, noting that the wind direction (panel (b)) was also significantly variable at heights up to $50 \mathrm{~m}$, and both are consistent with the IR imagery. The data indicate that the major clearances (e.g., Figure 12, panel (b)) in the fog occurred when winds became approximately northwest. It is not possible to deduce these clearances from the temperature and humidity data which show no significant perturbations at those times. It can be noted that the significant urban conurbation of Bedford lies a few $\mathrm{km}$ to the north west of Cardington and it is possible that conditions there did not favour fog formation such that air advecting from there was clear.

Figure 12, panel (d) shows the situation once the valley fog had dissipated (due to solar insolation). Visible on the horizon is a layer of fog which was advecting northward off the higher ground, and which subsequently engulfed the measurement site. Advection of fog from the surrounding higher ground over the measurement site is relatively common for this location and is a significant mechanism in the development of deeper fogs (> $50 \mathrm{~m}$ deep) there. Regular use of thermal IR imagery at the site has allowed such local effects to be better understood and quantified.

\section{Discussion and Conclusions}

The advent of relatively inexpensive thermal IR cameras sensitive in the 7-14 $\mu \mathrm{m}$ window has provided new data to analyse the dynamics of radiation fog. Our systems were mounted at high vantage points creating a 'birds-eye' view and set up to make time-lapse photography (at one frame per minute), allowing the creation of video footage which revealed the complexity of fog systems in nocturnal SBLs not previously seen. Important processes in fog evolution have been observed and elucidated in various trials such as the LANFEX campaign, including vertical fog growth, the role of advective compared to in situ processes, gravity currents, turbulence, and SBL dynamics within a valley system such as advection and sloshing. Other curious features such as isolated gravity waves have also been observed. Regarding the vertical growth of radiation fog, then when using IR video footage, it is normally relatively straightforward (compared to conventional observations) to establish whether the fog growth is due to local or non-local processes. The IR data show both occurring, and that in the latter situation of non-local growth, this usually results from fog which has formed on 
the higher ground surrounding Cardington advecting into the valley and engulfing the shallow fog present there.

Comparison of video footage with meteorological observations has revealed that many important processes occurring in fog evolution do not produce a conclusive signal in the meteorological measurements. For example, the complex processes occurring in the valley at Skyborry could not be deduced from the meteorological observations yet were clear in the IR video footage. Furthermore, establishing the reason for vertical fog growth or estimating fog depth is not always possible from conventional observations. In addition, the IR data have revealed instances when the proximity of a large building has influenced the meteorological measurements, which would not otherwise have been possible. Processes which created clearer signals in the meteorological data were sloshing and a gravity current. The former is recorded principally in the wind direction but leaves little impact on other parameters such as temperature and humidity. The latter produced a clear signal in winds, turbulence, visibility and temperature. Nonetheless, it is clear that use of thermal IR imagery can provide very useful insight into fog formation, development and dissipation.

Supplementary Materials: The following videos are available online at http://www.mdpi.com/2073-4433/11/ 3/240/s1, Video S1: skyborry_20150918_IR_fogpaper.mp4; Video S2: isolated_waves_20160106_IR_paper.mp4; Video S3: Turbulent_fog_20161003_IR_paper.mp4; Video S4: Gravity_curent_20161205_IR_paper.mp4; Video S5: Sloshing_fog_220161212_IR_paper.wp4; Video S6: Inhomogeneous_20161227_IR_fogpaper.wp4.

Author Contributions: Conceptualization, J.P.; methodology, J.P. and K.S.; software, J.P. and K.S.; formal analysis, J.P.; resources, J.P.; data curation, J.P. and K.S.; writing-original draft preparation, J.P.; writing-review and editing, J.P.; supervision, J.P. All authors have read and agreed to the published version of the manuscript.

Funding: This research received no external funding.

Acknowledgments: The authors wish to thank the staff at the Met Research Unit, Cardington for their help in collecting the data used in this study, and the three reviewers for their helpful comments.

Conflicts of Interest: The authors declare no conflict of interest.

\section{References}

1. Gultepe, I.; Tardif, R.; Michaelides, S.C.; Cermak, J.; Bott, A.; Bendix, J.; Müller, M.D.; Pagowski, M.; Hansen, B.; Ellrod, G.; et al. Fog Research: A Review of Past Achievements and Future Perspectives. Pure Appl. Geophys. 2007, 164, 1121-1159. [CrossRef]

2. Kulkarni, R.; Jenamani, R.K.; Pithani, P.; Konwar, M.; Nigam, N.; Ghude, S.D. Loss to Aviation Economy Due to Winter Fog in New Delhi during the Winter of 2011-2016. Atmosphere 2019, 10, 198. [CrossRef]

3. Forthun, G.M.; Johnson, M.B.; Schmitz, W.G.; Blume, J.; Caldwell, R.J. Trends in fog frequency and duration in the southeast United States. Phys. Geogr. 2006, 27, 206-222. [CrossRef]

4. Tanaka, H.; Honma, S.; Nishi, M.; Igarashi, T.; Teramoto, S.; Nishio, F.; Abe, S. Acid fog and hospital visits for asthma: An epidemiological study. Eur. Respir. J. 1998, 11, 1301-1306. [CrossRef] [PubMed]

5. Schemenauer, R.S.; Fuenzalida, H.; Cereceda, P. A Neglected Water Resource: The Camanchaca of South America. Bull. Am. Meteorol. Soc. 1988, 69, 138-147. [CrossRef]

6. Li, C.; Zelený, D.; Chytrý, M.; Chen, M.; Chen, T.; Chiou, C.; Hsia, Y.; Liu, H.; Yang, S.; Yeh, C.; et al. Chamaecyparis montane cloud forest in Taiwan: Ecology and vegetation classification. Ecol. Res. 2015, 30, 771-791. [CrossRef]

7. Baldocchi, D.; Waller, E. Winter fog is decreasing in the fruit growing region of the Central Valley of California. Geophys. Res. Lett. 2014, 41, 3251-3256. [CrossRef]

8. Steeneveld, G.J.; Ronda, R.J.; Holtslag, A.A.M. The Challenge of Forecasting the Onset and Development of Radiation Fog Using Mesoscale Atmospheric Models. Bound. Layer Meteorol. 2014, 154, 265-289. [CrossRef]

9. Price, J.D.; Lane, S.; Boutle, I.A.; Smith, D.K.E.; Bergot, T.; Lac, C.; Duconge, L.; McGregor, J.; Kerr-Munslow, A.; Pickering, M.; et al. 'LANFEX: A field and modelling study to improve our understanding and forecasting of radiation fog'. Bull. Amer. Meteorol. Soc. 2018, 99, 2061-2077. [CrossRef]

10. Price, J.D. On the formation and development of radiation fog: An observational study. Bound. Layer Meteorol. 2019, 172, 167-197. [CrossRef] 
11. Rees, J.M.; Anderson, P.S.; King, J.C. Observations of Solitary Waves in the Atmospheric Boundary Layer. Bound. Layer Meteorol. 1998, 86, 47-61. [CrossRef]

12. Cuxart, J.; Jimenez, M.A. Deep Radiation Fog in a Wide Closed valley: Study by Numerical Modelling and Remote Sensing. Pure Appl. Geophys. 2012, 169, 911-926. [CrossRef]

13. Bergot, T.; Escobar, J.; Masson, V. Effect of small-scale surface heterogeneities and buildings on radiation fog: Large-eddy simulation study at Paris-Charles de Gaulle airport. Q. J. Royal Meteorol. Soc. 2015, 141, 285-298. [CrossRef]

14. Nakanishi, M. Large-eddy simulation of radiation fog. Bound.-Layer Meteorol. 2000, 94, 461-493. [CrossRef]

15. Maronga, B.; Bosveld, F.C. Key parameters for the life cycle of nocturnal radiation fog: A comprehensive large-eddy simulation study. Q. J. Royal Meteorol. Soc. 2017, 143, 2463-2480. [CrossRef]

16. Katata, G. Fogwater deposition modeling for terrestrial ecosystems: A review of developments and measurements. J. Geophys. Res. Atmos. 2014, 119, 8137-8159. [CrossRef]

17. Mazoyer, M.; Lac, C.; Thouron, O.; Bergot, T.; Masson, V.; Musson-Genon, L. Large eddy simulation of radiation fog: Impact of dynamics on the fog life cycle. Atmos. Chem. Phys. 2017, 17, 13017-13035. [CrossRef]

18. Tav, J.; Masson, O.; Burnet, F.; Paulet, P.; Bourianne, T.; Conil, S.; Pourcelot, L. Determination of Fog-Droplet Deposition Velocity from a Simple Weighing Method. Aerosol Air Q. Res. 2018, 18, 103-113. [CrossRef]

19. Vermeulen, A.T.; Wyers, G.P.; Romer, F.G.; Van Leeuwen, N.F.M.; Draaijars, G.P.J.; Erisman, J.W. Fog deposition on a coniferous forest in the Netherlands. Atmos. Environ. 1997, 31, 375-386. [CrossRef]

(C) 2020 by the authors. Licensee MDPI, Basel, Switzerland. This article is an open access article distributed under the terms and conditions of the Creative Commons Attribution (CC BY) license (http://creativecommons.org/licenses/by/4.0/). 